\title{
Effect of wet mass on dextromethorphan hydrobromide matrix pellets
}

\author{
Mohamed Abbas Ibrahim ${ }^{1,2 *}$, Gamal Mohamed Mahrous ${ }^{1}$ \\ ${ }^{1}$ Department of Pharmaceutics, College of Pharmacy, King Saud University, KSA., Riyadh, Saudi Arabia, ${ }^{2}$ Department of \\ Pharmaceutics and Industrial Pharmacy, Faculty of Pharmacy, Al-Azhar University, Assiut, Egypt
}

\begin{abstract}
Dextromethorphan hydrobromide (DM) sustained release matrix pellets containing $10 \% \mathrm{w} / \mathrm{w}$ drug were prepared by an extrusion/spheronization technique. The effect of mixing different concentrations of ethyl cellulose (EC), hydroxypropyl methylcellulpse (HPMC K10), and Carbopol 934 with Avicel PH101 on the rheological properties of pellet wet mass was evaluated using mixer torque rheometry (MTR). The prepared pellets were characterized for size, drug content, and in-vitro DM release rate. The results showed that increasing the concentration of the hydrophobic polymer (EC) with Avicel PH101 decreased wet mass consistency, represented by mass mean line torque. Lower binder ratio was required for optimum wet massing, while mixing with swellable polymers (HPMC and Carbopol) caused a noticeable increase in both mean line torque and binder ratio. Combinations of HPMC and Carbopol at higher concentrations resulted in controlled in vitro release of DM from the prepared pellets. Furthermore, mathematical treatment of the in vitro release data of DM from the prepared pellets showed that all formulations except those containing 5\% Carbopol plus 5\% HPMC (F10) follow first order release. $n$ values of these formulation were in the range of 0.09-0.40, which support an anomalous non-Fickian release.
\end{abstract}

Keywords: Dextromethorphan hydrobromide. Matrix pellets. Extrusion spheronization. Mix torque rheometer (MTR).

\section{INTRODUCTION}

Pellets as a dosage form have several drug delivery and technological benefits in comparison to the conventional single-unit regimen. Less irritation of the gastro-intestinal tract and a lowered risk of side effects due to dose dumping are achieved by formulating drugs as pellets (Bechgaard, Nielsen, 1978). In addition, formulation and technological advantages are realized with pellets, such as better flow properties, low friability, narrow particle size distribution, ease of coating, and uniform packing. It was shown that pellets, as multi-unit dosage forms, have started to gain acceptance over conventional single units, for controlled release purposes (Mehta et al., 2001). The rapid and homogenous dispersion of pellets in the gastrointestinal tract results in maximized drug absorption, and reduces the fluctuations that may prevail in plasma levels. Therefore, the potential drug side effects associated with plasma

\footnotetext{
*Correspondence: Department of Pharmaceutics. College of Pharmacy, King Saud University, Riyadh 11454, P.O.Box 2457, Kingdom of Saudi Arabia. E-mail: abbma71@gmail.com
}

level changes can be minimized without lowering drug bioavailability. Additionally, owing to the homogeneous absorption from spherical multiparticulate systems, pellets minimize fluctuations in gastric emptying rates as well as overall transit times. Thus, minimization of both intra and inter-subject variations in plasma levels of single-unit regimens could be achieved.

The application of pellet- and granule-based controlled drug delivery systems was investigated by several studies. It is recommended to avoid the use of organic solvents or coating due to strict global requests of product safety. Industrial hygiene rules and FDA guidelines are being strengthened, restricting solvent use and exposure (Ibrahim, 2013). Furthermore, monitoring the coating procedures is tedious, and frequently encounters large variability (Heng, 2005). Many alternative techniques were studied for controlled drug delivery systems such as melt granulation (Schaefer, Holm, Kristensen, 1990), melt extrusion (Sprockel et al., 1997; De Brabander, Vervaet, Remon, 2003), melt dispersion (Follonier, Doelker, Cole, 1994), and melt solidification (Siepmann et al., 2006). In addition, development of matrix sustained release pellets 
saves time and money by omitting the coating procedure (Ghali, Klinger, Schwartz, 1989). Such systems retard the penetration of aqueous fluids into the formulation and hence slow the rate of drug release.

The rheological properties of pellets' wet masses could affect the release rates from pellet formulations. These properties can be effectively assessed by a mixer torque rheometer (Chatlapalli, Rohera, 2002; Soh, Liew, Heng, 2006). Ibrahim (2013) showed that an inverse relation was observed between the rheological character of pellet wet mass (expressed by peak torque) and in vitro release rate of mefenamic acid from sustained release matrix pellets. Additionally, the results obtained by Ibrahim and Shazly (2014) revealed that diclofenac sodium release from pellets was governed by the molecular weight of PEG used, since increasing the molecular weight of PEG resulted in slowing the drug release rate from pellets, while increasing its concentration enhanced the release rate. This was attributed to increasing the peak torque of pellet wet mass by increasing PEG molecular weight and lowering it by increasing PEG level.

Dextromethorphan hydrobromide (DM) is a nonnarcotic antitussive agent generally used as an ingredient in cough and cold remedies. The drug is a white crystalline powder with a molecular weight of 370.3 , and its water solubility is $15 \mathrm{mg} / \mathrm{mL}$ at $25^{\circ} \mathrm{C}$ (Budavari, 1996). The dosage of the drug is usually three to four times a day because of its short half-life $(2.7 \mathrm{~h})$. Therefore, DM sustained release dosage forms were developed to avoid repeated administration, and to increase patient compliance (Pongjanyakul et al., 2005). Bharag, Taka and Sakr (2006a) reported that extended-release DM matrix tablets were developed using HPMC K100LV/ methacrylic acid copolymer (Eudragit ${ }^{\circledR}$ L100-55) combination, and polyvinyl acetate-povidone (PVAP). Both selected extended-release DM matrix tablets followed square root of time-dependent kinetics for drug release, indicating a diffusion-controlled release mechanism. In another study, Bharag, Taka and Sakr (2006b) reported that the selected extended-release HPMC/Eudragit and PVAP dextromethorphan tablets were not bioequivalent to the marketed capsule product, TussHustenstiller Retardkapslen ${ }^{\circledR}$. However, the tablets had improved bioavailability as shown by area under the curve $(0-\infty)$. The aim of the present study was to investigate the effect of different polymers on the dextromethorphan $\mathrm{HBr}$ matrix pellets wet massing properties, particle size and drug release rate.

\section{MATERIAL AND METHODS}

DM was kindly supplied by RIYADH PHARMA
(Riyadh, Saudi Arabia). Microcrystalline cellulose (Avicel ${ }^{\circledR}$ PH-101) was purchased from Serva Feinbiochemica, (Heidelberg, Germany). Ethylcellulose (EC) was gifted by Colorcon (United Kingdom). High viscosity-grade hydroxypropyl methylcellulose, Methocel K10;HPMC, was kindly donated by DOW (Midland, MI, United States). Carbopol 934 was obtained from Goodrich chemical Co. (England).

\section{METHODOLOGY}

\section{Characterization of pellets wet masses by mixer torque rheometer}

The wet mass before pelletization procedures (extrusion/spheronization) was evaluated by the mixer torque rheometer (MTR). MTR consists of a 135-mL capacity stainless-steel bowl equipped with two mixing blades with a rotational speed of 20-150 rpm (MTR-3, Caleva, Dorset, England). A sample of 15-30 g of dry powder mixture is sufficient to cover the mixer blades in accordance to the powder bulk density. With the help of a torque arm connected from the main body of the mixer to a calibrated load transducer, the wet mass torque was measured directly on the mixer bowl. For all studies, a mixer speed of $50 \mathrm{rpm}$ was applied. Data acquisition and analyses were performed using software provided by the equipment manufacturer.

Individual powder ingredients were homogeneously mixed using turbula mixer (type S27, Erweka, Apparatebau, Germany). Fifteen grams of dry powder blend was used in the wet massing studies. Two milliliters of binder solution (water in this study) was added at intervals over 12 wet massing cycles, each wet massing cycle consisted of a one-minute mixing period and a 20 -second torque data logging. The values of mean line torque (NM) were monitored during the wet massing procedures.

\section{Preparation of pellets (extrusion/spheronization procedures)}

The compositions of different pellet formulations containing $10 \% \mathrm{w} / \mathrm{w}$ DM are illustrated in Table I. Water was used as a binder solution for the formation of wet mass prior to extrusion/spheronization to prepare DM-loaded pellets. The choice of the water volume required for wet massing was based on the highest torque value observed by MTR. Formula weights of the active ingredient and the other pellet excipients were homogeneously mixed in turbula mixer, and the powder mixture was wetted with a suitable volume of water. Thereafter, the wet mass 
Effect of wet mass on dextromethorphan hydrobromide matrix pellets

TABLE I - Composition of various DM pellet formulations

\begin{tabular}{|c|c|c|c|c|c|c|c|c|c|c|c|c|}
\hline \multirow{2}{*}{ Ingredient (\%w/w) } & \multicolumn{12}{|c|}{ Pellet formulations } \\
\hline & F0 & F1 & F2 & F3 & F4 & F5 & F6 & F7 & F8 & F9 & F10 & F11 \\
\hline EC & & 5 & 10 & 20 & & & & & & & & \\
\hline HPMC K10 & & & & & 5 & 10 & 20 & & & & 5 & 10 \\
\hline Carbopol 934 & & & & & & & & 5 & 10 & 20 & 5 & 10 \\
\hline DM & 10 & 10 & 10 & 10 & 10 & 10 & 10 & 10 & 10 & 10 & 10 & 10 \\
\hline Avicel PH101 & 90 & 85 & 80 & 70 & 85 & 80 & 70 & 85 & 80 & 70 & 80 & 70 \\
\hline Water (Binder) & QS & & & & & & & & & & & \\
\hline
\end{tabular}

was extruded at a speed of $90 \mathrm{rpm}$ with a screen pore size of $1 \mathrm{~mm} \varnothing$ (Mini Screw Extruder, Model MSE1014, Caleva, Dorset, England). The resulting extrudates were spheronized in a spheronizer (Model 120, Caleva, Dorset, England) at a rotation speed of $700 \mathrm{rpm}$, for 5 minutes in a rotating plate of regular cross-hatch geometry. Pellets were then placed on a tray and dried in a hot oven at $50-60^{\circ} \mathrm{C}$ for 6 hours.

\section{Drug content}

The prepared pellets were characterized for their DM content in triplicate. In brief, a specific weight of pellets was crushed in a porcelain mortar and about $20 \mathrm{mg}$ of the powder was dispersed in $500 \mathrm{~mL}$ phosphate buffer $(\mathrm{pH}=6.8)$ under sonication for 10 minutes. The dispersion was then filtered using a cellulose nitrate filter with pores of $0.2 \mu \mathrm{m}$ in diameter (Sartorius, Göttingen, Germany) and the absorbance was measured spectrophotometrically at $278 \mathrm{~nm}$ (UV-2800 spectrophotometer, Labomed Inc., USA). Drug content was computed from the standard curve.

\section{Particle size analysis}

DM-loaded, sustained release matrix pellets were investigated for their size distribution using laser light diffraction technique (Mastersizer Scirocco 2000, Malvern Instruments, Grovewood Road, U. K.). A pellet sample weight of about $300 \mathrm{mg}$ was introduced to the sample micro feeder. All samples were analyzed 5 times and average results were taken. The pellets 10th $(\mathrm{d}(0.1)), 50$ th $(\mathrm{d}(0.5))$ and 90th $(\mathrm{d}(0.9))$ percentiles were used to characterize the pellets size distribution. The approximate mean diameter was taken as the average of $\mathrm{d}(0.1), \mathrm{d}(0.5)$, and $\mathrm{d}(0.9)$ values.

To investigate the pellet particle size distribution, the span value was calculated from the equation given below (Chen et al., 2004). Small values of span refer to a narrow particle size distribution.

$$
\text { Span }=[d(0.9)-d(0.1)] / d(0.5)
$$

\section{In vitro dissolution studies}

The dissolution rate studies for DM-loaded pellets were performed using the USP dissolution basket method (apparatus 1). Pellets weighing equivalent to $50 \mathrm{mg} \mathrm{DM}$ were added to $500 \mathrm{~mL}$ of dissolution medium (phosphate buffer, $\mathrm{pH}$ 6.8). The temperature was maintained at $37 \pm 0.5^{\circ} \mathrm{C}$. An accurately weighed amount of the prepared pellets was added to each flask. For each sample formula, drug dissolution was analyzed in triplicate and absorbance was measured spectrophotometrically at $278 \mathrm{~nm}$ up to 6 hours. The percentage of drug released was determined as a function of time using a calibration curve constructed at the same wavelength.

\section{Statistical analysis}

The results were analyzed by using the software GraphPad Prism5 (GraphPad Software, La Jolla, USA) applying one-way ANOVA. Differences between formulations were considered to be significant at $p \leq 0.05$.

\section{RESULTS AND DISCUSSION}

\section{Characterization of pellet wet masses by mixer torque rheometer}

Wet mass studies of Avicel PH101 mixed with different concentrations of EC, HPMC, and Carbopol (using water as the binder liquid) were conducted to determine the water/powder ratio required to attain a maximum torque value for powder wet massing prior to extrusion/spheronization procedures. The MTR curve of Avicel PH101 itself showed the progress of liquid saturation phases. The mean torque value of Avicel PH101 wet mass was found to increase by increasing the added binder volume. Different mean line torque patterns were 
exhibited in case of Avicel PH101-EC systems, Figure 1. A noticeable decrease of MTR curve area was observed upon increasing the EC weight ratio. This results from progression to liquid saturation phase, which prevails at lower water/powder ratio. The lowest peak torque value was recorded in case of the Avicel PH101-EC system containing $20 \% \mathrm{EC}(0.279 \mathrm{Nm})$. Additionally, the water/ powder ratio $(\mathrm{mL} / \mathrm{g})$ required for peak torque for Avicel PH101-EC systems was found to be less than that of Avicel PH101 alone (Figure 1). However, the water/powder ratios $(\mathrm{mL} / \mathrm{g})$ for all Avicel PH101-EC systems were the same for all EC weight ratios (1: $1 \mathrm{~mL} / \mathrm{g}$; Figure 1). Figure 2 illustrates the MTR patterns of Avicel PH101-HPMC systems. Binary system containing 5\% and 10\% HPMC exhibited high peak torque values $(1.428 \mathrm{Nm}$ and 1.612 $\mathrm{Nm}$, respectively) in comparison to Avicel PH101, but $10 \%$ HPMC caused reduction of the binder ratio in contrast to that recorded with the system containing 5\% HPMC or Avicel PH101 alone (Figure 2). Mixing HPMC with Avicel PH101 in 20\% w/w resulted in formation of a very sticky mass at a low binder ratio $(0.67 \mathrm{~mL} / \mathrm{g})$.

The MTR patterns of Carbopol-Avicel PH101 systems showed that by increasing Carbopol weight ratio, an increase in the wet mass peak torques was observed (Figure 3$)$. In addition, lower binder ratio $(1: 1 \mathrm{~mL} / \mathrm{g})$ was observed for the wet mass of Avicel PH101 mix containing $10 \%$ Carbopol. It is worth noting that Avicel PH101Carbopol system containing 20\% Carbopol showed very high viscosity when mixed with the binder solution that was difficult to be measured by the MTR. Parker, Rowe and Upjohn (1990) showed that the magnitude of binding liquid, when spreading and wetting the powder, and the interaction with the granulating liquid, are responsible for controlling the relative positions of peak values for mean line torque. Pendular and funicular wet massing phases are characterized by a gradually increasing network of liquid bridges. These two phases together are expected to result in an increase in powder mass cohesiveness and, in turn, an increased torque on the mixer (Parker, York, Rowe, 1990; Luukkonen et al., 1999). In case of filling all the air spaces in the granular material with the binding liquid, the capillary phase was attained at the maximum on the curve. Further addition of the binding liquid caused a decrease in wet mass torque value, as a slurry of particles dispersed in liquid is formed.

\section{Pellet sizes}

Table II illustrates the sizes of the prepared pellet formulations using laser 45 diffractometry represented by the computed values of volume weighted mean particle

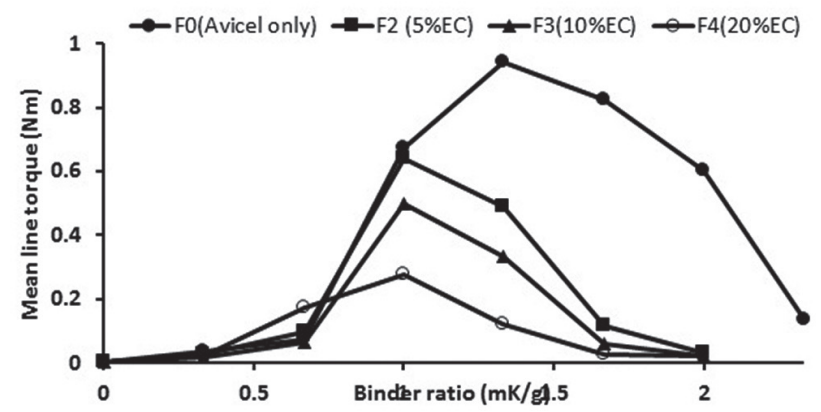

FIGURE 1 - Effect of different concentrations of EC on mean torque of Avicel PH101 ${ }^{\circledR}$ wet masses.

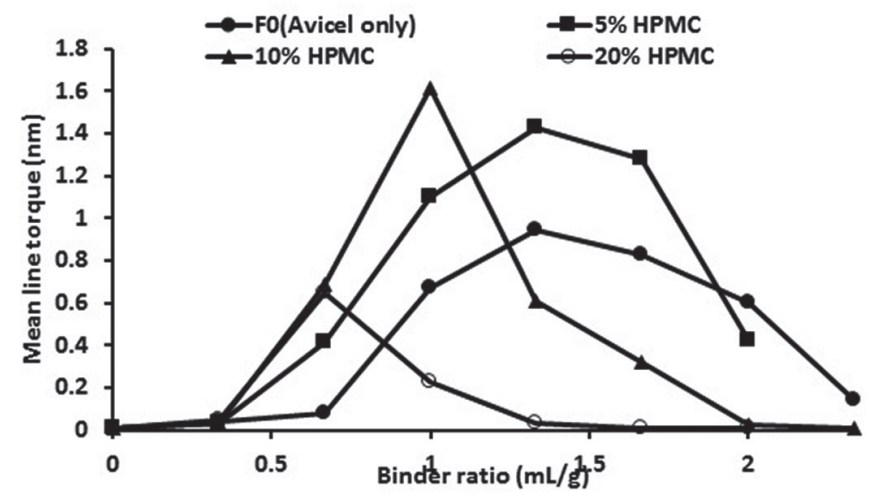

FIGURE 2 - Effect of different concentrations of HPMC K10 on mean torque of Avicel PH101 ${ }^{\circledR}$ wet masses.

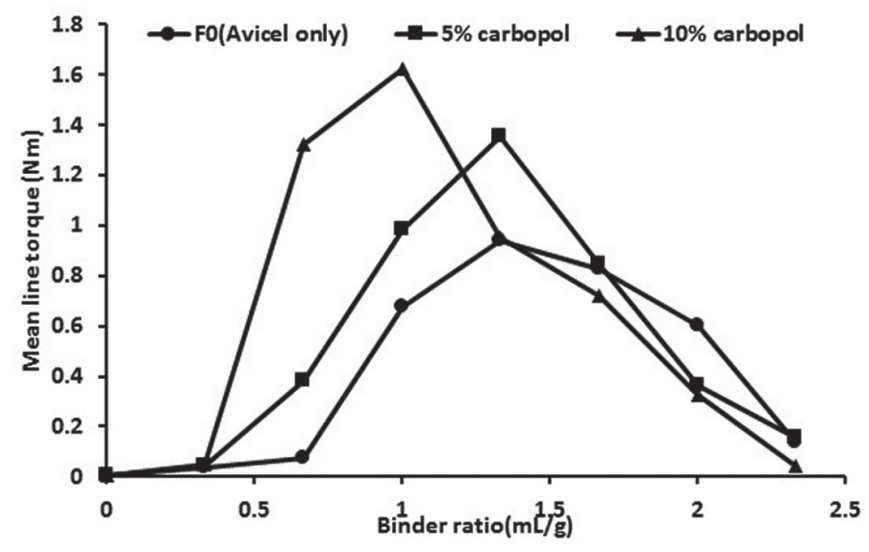

FIGURE 3 - Effect of different concentrations of Carbopol on mean torque of Avicel PH101 ${ }^{\circledR}$ wet masses.

size and the $d(0.1), d(0.5)$ and $d(0.9)$. The average values of the volume weighted means for all pellet formulations were found between $1242.7 \mu \mathrm{m}-878.5 \mu \mathrm{m}$ with small span values (0.62-0.94) indicating a narrow particle size distribution and high pellet sphericity (Sinha et al., 2010). In case of pellet formulae containing EC (F1-F3), increasing EC weighted ratio resulted in reduced size of the prepared pellets. In contrast, increasing the HPMC concentration in pellet formulations (F4-F6) was accompanied by increasing the pellets' sizes. Moreover, 
Effect of wet mass on dextromethorphan hydrobromide matrix pellets

TABLE II -Volume weighted mean particle size and the $\mathrm{d}(0.1), \mathrm{d}(0.5), \mathrm{d}(0.9)$ and span values of different pellet formulae loaded with $\mathrm{DM}(10 \% \mathrm{w} / \mathrm{w}$ as determined by laser diffractometry $)$

\begin{tabular}{lccccc}
\hline Pellets Formulation & Mean $(\boldsymbol{\mu m})$ & $\mathbf{D}(\mathbf{0 . 1}) \boldsymbol{\mu m}$ & $\mathbf{d}(\mathbf{0 . 5}) \boldsymbol{\mu m}$ & $\mathbf{d}(\mathbf{0 . 9}) \boldsymbol{\mu m}$ & Span value \\
\hline F0 & 1032.5 & 670.4 & 1020.5 & 1411.2 & 0.73 \\
F1 & 974.5 & 525.4 & 987.6 & 1385.4 & 0.87 \\
F2 & 912.5 & 485.4 & 895.4 & 1305.4 & 0.91 \\
F3 & 878.5 & 465.7 & 877.4 & 1289.7 & 0.94 \\
F4 & 1175.5 & 690.4 & 1089.4 & 1511.1 & 0.62 \\
F5 & 1235.4 & 728.5 & 1132.7 & 1568.4 & 0.74 \\
F6 & 1248.6 & 720.1 & 1115.4 & 1420.1 & 0.81 \\
F7 & 1098.5 & 697.4 & 1112.4 & 1487.5 & 0.71 \\
F8 & 1242.7 & 718.7 & 1164.2 & 1518.4 & 0.69 \\
F9 & $\mathrm{ND}$ & $\mathrm{ND}$ & $\mathrm{ND}$ & $\mathrm{ND}$ & $\mathrm{ND}$ \\
F10 & 1280.5 & 780.6 & 1203.6 & 1590.4 & 0.71 \\
F11 & 1260.3 & 760.4 & 1150.3 & 1476.7 & 0.80 \\
\hline
\end{tabular}

the pellet formulations containing Carbopol showed that increasing Carbopol level from 5\% to $10 \%$ resulted in increasing the pellet size, which could be attributed to the increased torque value of pellets wet mass containing $10 \%$ Carbopol more than that contains 5\% (Figure 3). It is worth mentioning that the pellet formula containing $20 \%$ Carbopol (F9) showed irregular shapes due to the very high wet mass consistency, and therefore, the particle size was not determined for such formula. Furthermore, in case of pellet formulations containing blends of HPMC and Carbopol (F11 and F12), increasing the level of each polymer in the blend resulted in increasing the pellet size. Ibrahim (2013) showed an inverse relation between the peak torque of the pellets wet masse and size. Moreover, Kristensen, Schæfer and Kleinebudde (2000) found a linear correlation between the wet mass peak torque and pellet size for pellet formulas containing $80 \%(\mathrm{w} / \mathrm{w})$ Avicel PH101.

\section{In vitro release from pellets}

Pellets containing Avicel PH101 showed fast release of DM. The release was complete within 30 minutes. Addition of polymers delayed this pattern of release. However, pellets containing 5, 10, and 20\% EC showed a faster release of DM than the other two polymers, as shown in Figure 4. The T80\% value was less than 30 minutes for the three tested formulae.

Figure 5 shows the in vitro DM release from pellets containing HPMC. It was observed that increasing the level of HPMC from $5 \%$ to $20 \%$ slowed drug release. It was interesting that DM release from pellets containing
$20 \%$ HPMC was faster than that containing $10 \%$ HPMC. This observation could be explained on the basis of MTR results. In all formulations containing $20 \%$ polymer, there was a reduction in the binder ratio in contrast to that recorded with the system containing $5 \%$ or $10 \%$, which could decrease the hydration of HPMC. DM release is controlled by the hydration of HPMC, which formed a gelatinous barrier layer at the surface of the matrix. Increasing HPMC concentration from 5 to $10 \%$ showed a decrease in DM release, in which (F5), $80 \%$ of DM was released after 30 minutes.

The effect of Carbopol level on DM release is shown in Figure 6. The drug release decreased as the amount of Carbopol level in the pellets increased from 5 to $10 \%$, relative to control. The T80\% value (time for $80 \% \mathrm{DM}$ release) was 20, 30, 55, and 30 minutes for F0 (control), F7, F8, and F9 (contain 5, 10, and 20\% Carbopol), respectively. This could be attributed to the fact that the gel layer formed around the pellets became stronger with less regions of microviscosity as a result of the anionic character of Carbopol.

On the basis of the above results, it was found that Carbopol polymer at $10 \%$ is more effective than cellulosic materials in sustaining the DM release when used at the same levels. Carbopol is a lightly crosslinked polymer, unlike the cellulosic materials, which are linear. In matrix pellets prepared with linear hydrophilic polymers (such as HPMC, which do not have a covalently crosslinked structure), a gelatinous layer is formed on the surface of the pellets on hydration. On the other hand, the crosslinked network of Carbopol enables the entrapment of drug in the hydrogel domain. These hydrogels erode slower than linear 
polymers (Khan, Jiabi, 1998). Figure 7 shows the effect of blending Carbopol 934 and HPMC K15M (1:1) on the in vitro release of DM. Combination of Carbopol and HPMC at different proportions ( 5 and $10 \%)$ significantly $(P<0.05)$ retarded the release of DM, relative to Carbopol or HPMC alone (F10, F11). These data show that a combination of anionic polymer (Carbopol 934) and nonionic HPMC produce a synergistic effect in delay of DM release. The T $80 \%$ value increased from $30 \mathrm{~min}(\mathrm{~F} 5)$ and 55 minutes (F6) to 150 minutes (F10). This is likely due to stronger hydrogen bonding between the carboxyl groups of Carbopol and the hydroxyl groups of HPMC, leading to stronger crosslinking between the two polymers, and a synergistic increase in viscosity. This is reflected in the increased mean line torque value of pellet wet mass for formulations containing either Carbopol or HPMC, relative to those containing EC. Therefore, a noticeable inhibition of drug release was exerted by the matrix pellet formulations containing Carbopol and HPMC. Samani, Montaseri and Kazemi (2003) showed that a combination of anionic polymer Carbopol 940 with nonionic HPMC produced a synergistic increase in viscosity. The authors attributed this finding to the stronger hydrogen bonding between carboxyl groups of Carbopol and hydroxyl groups of HPMC, leading to a stronger crosslinking between the two polymers, diminishing fluctuations in drug release. This behavior of HPMC and Carbopol blend has been also reported by Rao, Veni and Jayasagar (2001) and Anlar et al. (1994). These studies reported that an interpolymer complex was formed in solution between HPMC and Carbopol, and they attributed this phenomenon to an interaction between hydroxyl groups of HPMC and carboxyl groups of Carbopol. In our previous study, we found such interaction and elucidated it using IR spectroscopy. The results of IR spectra for Carbopol-HPMC physical mixture in comparison with Carbopol-HPMC matrix after soaking confirmed these suggestions (Fayed et al., 2011).

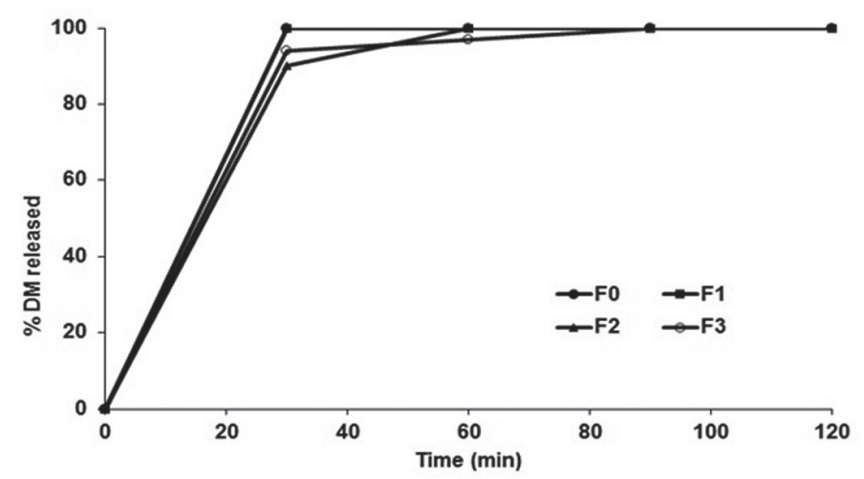

FIGURE 4 - In vitro release profiles of DM from pellets formulations prepared from different EC concentrations.

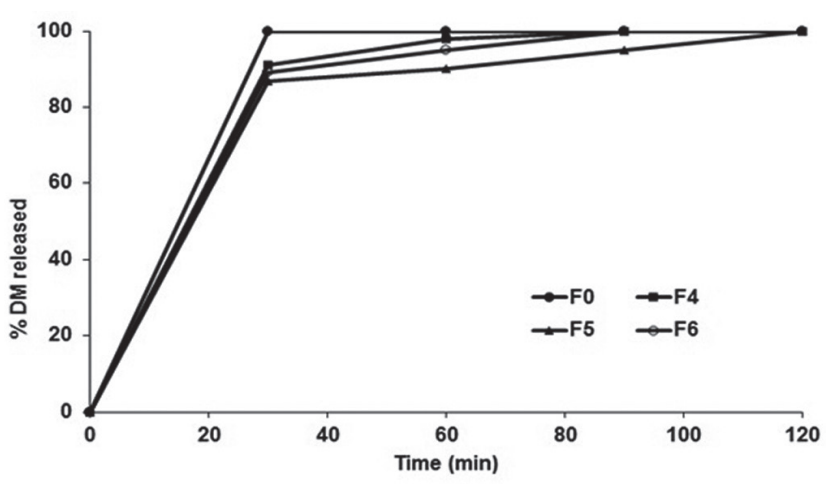

FIGURE 5 - In vitro release profiles of DM from pellets formulations prepared from different HPMC K10 concentrations.

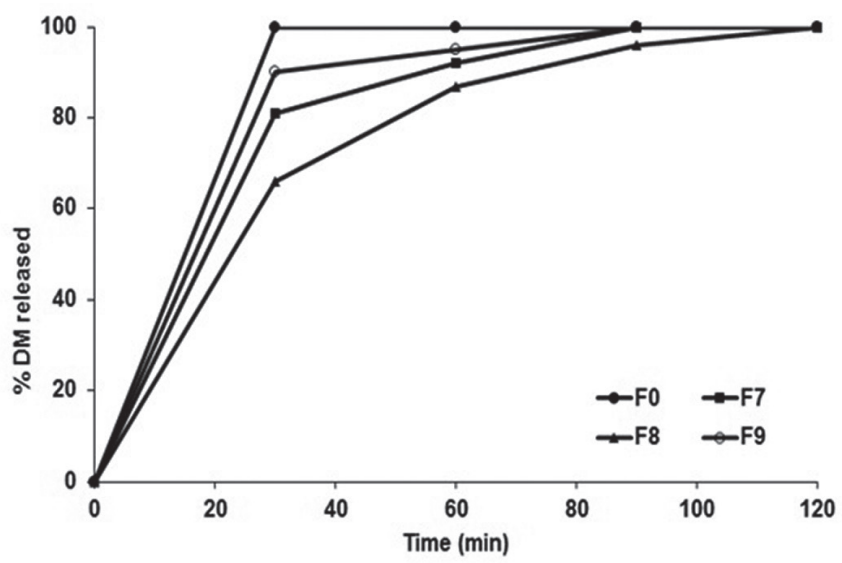

FIGURE 6 - In vitro release profiles of DM from pellets formulations prepared from different carbopol concentrations.

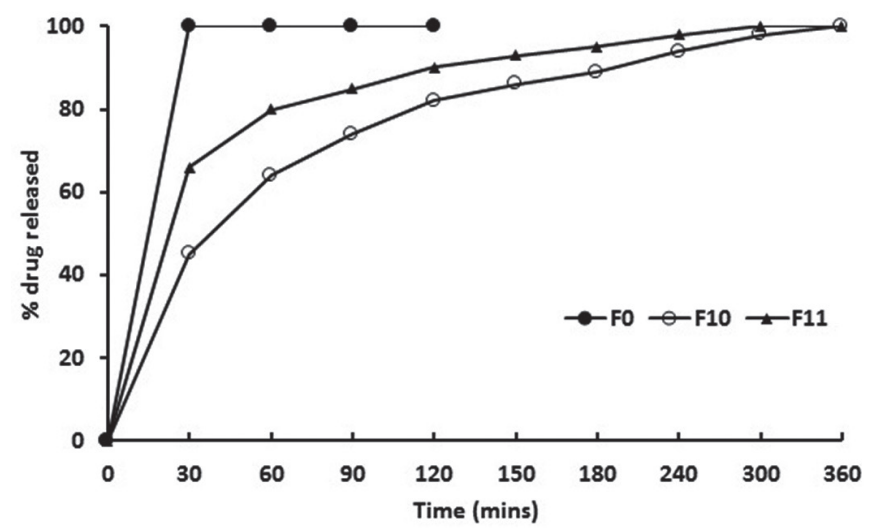

FIGURE 7 - In vitro release profiles of DM from pellets formulations F10 and F11 compared to F0.

\section{Kinetic modeling of the in vitro release data}

In order to determine the release model which best describes the pattern of drug release, the in-vitro release data were fitted to zero order, first order (Martin, 1993) and diffusion controlled release mechanisms according to 
the simplified Higuchi model (Higuchi, 1962).

a- Zero-order Kinetic model:

$$
\mathrm{C}=\mathrm{Co}-\mathrm{Kot} \text {. }
$$

b- First-order Kinetic model:

$$
\log \mathrm{C}=\log \mathrm{Co}-\mathrm{Kt} / 2.303
$$

c- Higashi diffusion model:

$$
\mathrm{Q}=2 \operatorname{Co}(\mathrm{Dt} / \pi)^{1 / 2}
$$

where: $\mathrm{Co}=$ initial drug concentration; $\mathrm{C}=$ drug concentration (remaining) at time $\mathrm{t}$; $\mathrm{t}=$ time of release; $\mathrm{Q}=$ amount of drug released/unit area; $\mathrm{Ko}=$ zero order rate constant, $\mathrm{K}=$ first order rate constant and $\mathrm{D}=$ diffusion Coefficient and it was calculated according to the following equation.

\section{$\mathrm{D}=($ Slope $/ 2 \mathrm{Co}) 2 \pi$}

The preference of a certain mechanism was based on the correlation coefficient (r) for the parameters studied, where the highest correlation coefficient is preferred for the selection of mechanism of release (Samuelov et al., 1979)

Successive evidence of the relative validity of diffusion and first order models obtained by analyzing the data using the following equation (Ritger, Peppas, 1987).

$$
\mathrm{Mt} / \mathrm{M}_{\infty}=\mathrm{K} \cdot \mathrm{t}^{1 / 2}
$$

where $\mathrm{Mt} / \mathrm{M} \infty$ is the fraction released by the drug at time $\mathrm{t}, \mathrm{K}$ is a constant incorporating structural and geometric characteristic and $\mathrm{n}$ is the release exponent characteristic for the drug transport mechanism. When $\mathrm{n}=0.5$, Fickian diffusion is observed and the release rate in dependent on $\mathrm{t}$, while $0.5<\mathrm{n}<1.0$ indicate anomalous (non Fickian) transport and when $n=1$, the release is zero order.
The mathematical treatment of the vitro release data of DM from the prepared pellets are presented in Table III. Based on the correlation coefficient values ( $r$ ), the results of the formulations that showed rapid release rate (biphasic first order), while the formulations containing polymer combination showed an anomalous non-Fickian release as indicated from the $\mathrm{n}$ values.

\section{CONCLUSION}

DM sustained release matrix pellets containing $10 \% \mathrm{w} / \mathrm{w}$ drug with extended release were successfully prepared by extrusion/spheronization technique. The effect of mixing different concentrations of EC, HPMC K10, and Carbopol 934 with Avicel PH101 on the rheological properties of pellet wet mass demonstrated that increasing the mixed concentration of the hydrophobic polymer (EC) with Avicel PH101 caused a reduction in wet mass consistency. Lower binder ratio was required for optimum wet massing, while mixing the swellable polymers, HPMC and Carbopol, caused a noticeable increase in both the mean torque and binder ratio. The average pellet sizes were found in the range of $878-1280 \mu \mathrm{m}$. An inverse proportionality was observed between wet mass mean line torque and pellets' sizes. The wet mass characteristics of the prepared pellets had a pronounced impact on the in vitro DM release rate. it was found that Carbopol polymer at $10 \%$ is more effective than cellulosic materials in sustaining the DM release, when used at the same levels.

Moreover, combination of HPMC and Carbopol resulted in improved control of the in vitro release rate of DM. The results showed that a combination of anionic polymer (Carbopol 934) and nonionic HPMC produced a synergistic effect in delaying DM release Furthermore, the mathematical treatment of the vitro release data of

TABLE III - Kinetic modeling of drug release form pellets containing DM

\begin{tabular}{lcccccc}
\hline \multirow{2}{*}{ Release Model } & & \multicolumn{5}{c}{ Pellet Formulations } \\
\cline { 3 - 7 } Zero order & $\mathbf{r}$ & $\mathbf{F 2}$ & $\mathbf{F 5}$ & $\mathbf{F 8}$ & $\mathbf{F 1 0}$ & $\mathbf{F 1 1}$ \\
\hline \multirow{2}{*}{ First order } & $\mathbf{K}_{\mathbf{0}}(\mathbf{m g} \mathbf{\%} / \mathbf{m i n})$ & 0.756 & 0.786 & 0.879 & 0.913 & 0.867 \\
& $\mathbf{r}$ & 0.947 & 0.964 & 0.975 & 0.976 & 0.956 \\
Higuchi diffusion & $\mathbf{K 1}(\mathbf{m i n}-\mathbf{1}) \mathbf{x} \mathbf{1 0}^{\mathbf{3}}$ & 35.66 & 34.8 & 33.6 & 9.2 & 14,95 \\
\hline \multirow{2}{*}{ Log Q Vs log t } & $\mathbf{r}$ & 0.912 & 0.925 & 0.979 & 0.991 & 0.972 \\
& $\mathbf{K h}\left(\mathbf{m g} / \mathbf{m}^{\prime} / \mathbf{m i n}^{\mathbf{1} / 2}\right.$ & 9.17 & 9.10 & 9.73 & 6.83 & 7.90 \\
\hline
\end{tabular}


DM from the prepared pellets showed an anomalous nonFickian release.

\section{ACKNOWLEDGEMENT}

The authors extend their appreciation to the Deanship of Scientific Research at King Saud University for funding the work through the research group project No. RG-1435-80.

\section{REFERENCES}

Anlar S, Capan Y, Güven O, Göğüş A, Dalkara T, Hincal AA. Formulation and in vitro-in vivo evaluation of buccoadhesive morphine sulfate tablets. Pharm Res. 1994;11(2):231-6.

Bechgaard H, Nielsen GH. Controlled-release multiple-units and single-unit doses. A literature review. Drug Dev Ind Pharm. 1978;4(1):53-67.

Bharag SS, Taka S, Sakr A. Development and in vivo evaluation of extended release dextromethorphan tablets. Pharm Ind. 2006;68(1):116-9.

Bharag SS, Taka, S, Sakr A. Development and in vivo evaluation of extended release dextromethorphan tablets. Pharm Ind. 2006;68(1):247-9.

Budavari S (editor). The Merck Index: an encyclopedia of chemicals, drugs, and biologicals. 12th ed. Whitehouse Station: NJ Merck \& Co.; 1996.

Chatlapalli R, Rohera BD. Study of effect of excipient source variation on rheological behavior of diltiazem HCl-HPMC wet masses using a mixer torque rheometer. Int J Pharm. 2002;238(1-2):139-51.

Chen PC, Park YJ, Chang LC, Kohane DS, Bartlett RR, Langer $\mathrm{R}$, et al. Injectable microparticle-gel system for prolonged and localized lidocaine release. I. In vitro characterization. J Biomed Mater Res A. 2004;70(3):412-9.

De Brabander C, Vervaet C, Remon JP. Development and evaluation of sustained release mini-matrices prepared via hot melt extrusion. J Control Release. 2003;89(2):235-47.

Fayed MH, Mahrous GM, Ibrahim MA, Sak A. Influence of Carbopol 71G-NF on the release of dextromethorphan hydrobromide from extended-release matrix tablets. Pharm Dev Technol. 2001;18(5):971-81.
Follonier N, Doelker E, Cole ET. Evaluation of hot melt extrusion as a new technique for the development of polymer base pellets for sustained release capsules containing high loadings of freely soluble drugs. Drug Dev Ind Pharm. 1994;20(8):1323-39.

Ghali ES, Klinger GH, Schwartz JB. Thermal treatment of beads with wax for controlled release. Drug Dev Ind Pharm. 1989;15(9):1311-28.

Heng PW. 15th International Symposium on Microencapsulation, Parma (Italy), September, 2005:18-21.

Higuchi WI. Analysis of data on medicament release from ointments. J Pharm Sci. 1962;51:802-4.

Ibrahim MA. Formulation and Evaluation of Mefenamic Acid Sustained Release Matrix pellets. Acta Pharm. 2013;63(1):8598.

Ibrahim MA, Shazly GA. Evaluation of diclofenac sodium sustained release matrix pellets: impact of polyethylene glycols molecular weight. Acta Pol Pharm Drug Res. 2014;71(5):82131.

Khan GM, Jiabi Z. Formulation and in vitro evaluation of ibuprofen-Carbopol 974P-NF controlled release matrix tablets. III: Influence of co-excipients on release rate of the drug. J Control Release 1998;54(2):185-90.

Kristensen J, Schaefer T, Kleinebudde P. Direct pelletization in a rotary processor controlled by torque measurements. I: Influence of process variables. Pharm Dev Technol. 2000;5(2):247-56.

Luukkonen P, Schæfer T, Hellén L, Juppo AM, Yliruusi J. Rheological characterization of microcrystalline cellulose and silicified microcrystalline cellulose wet masses using a mixer torque rheometer. Int J Pharm. 1999;188(2):181-92.

Martin A. Physical Pharmacy. 4th ed. U.S.A: Lea and Febiger; 1993. p. 287-497.

Mehta KA, Kislalioglu MS, Phuapradit W, Malick AW, Shah NH. Release performance of a poorly soluble drug from a novel, Eudragit ${ }^{\mathbb{Q}}$-based multi-unit erosion matrix. Int J Pharm. 2001;213(1-2):7-12.

Parker MD, Rowe RC, Upjohn NG. Mixer torque rheometry: A method for quantifying the consistency of wet granulations. Pharm Tech Int. 1990;2(9):50-64. 
Parker MD, York P, Rowe RC. Binder-substrate interactions in wet granulation. 1: The effect of binder characteristics. Int $\mathrm{J}$ Pharm. 1990;64(2-3):207-16.

Pongjanyakul T, Parakongpan S, Rungsardthong U, Chancham P, Priprem A. Characteristics and in vitro release of Dextromethorphan resinates. Powder Technol. 2005;152(13):100-6.

Ritger PL, Peppas NA. A simple equation for description of solute release ii. fickian and anomalous release from swellable devices. J Control Release. 1987;5(1):37-42.

Rao YM, Veni JK, Jayasagar G. Formulation and evaluation of diclofenac sodium using hydrophilic matrices. Drug Dev Ind Pharm. 2001;27(8):759-66.

Samani SM, Montaseri H, Kazemi A. The effect of polymer blends on release profiles of diclofenac sodium from matrices. Eur J Pharm Biopharm. 2003;55(3):351-5.

Samuelov Y, Donbrow M, Friedman M. ustained Release of Drugs from Ethylcellulose-Polyethylene Glycol Films and Kinetics of Drug Release. J Pharm Sci. 1979;68(3):325-9.
Schaefer T, Holm P, Kristensen HG. Melt granulation in a laboratory scale high shear mixer. Drug Dev Ind Pharm. 1990;19(8):1249-77.

Siepmann F, Muschert S, Flament MP, Leterme P, Gayot A, Siepmann J. Controlled drug release from Gelucirebased matrix pellets: Experiment and theory. Int J Pharm. 2006;317(2):13643.

Sinha VR, Aggarwal A, Srivastava S, Goel, H. Influence of operational variables in multi-particulate delayed release systems for colon-targeted drug delivery of celecoxib using extrusion spheronization. Asian J Pharm. 2010;4(2):102-9.

Soh JLP, Liew CW, Heng PWS. Torque rheological parameters to predict pellet quality in extrusion-Spheronization. Int J Pharm. 2006;315(1-2):99-109.

Sprockel OL, Sen M, Shivanand P, Prapaitrakul W. A melt extrusion process for manufacturing matrix drug delivery systems. Int J Pharm. 1997;155(2):191-9.

Received for publication on $03^{\text {rd }}$ December 2016 Accepted for publication on $28^{\text {th }}$ March 2018 